\title{
An Exploratory Study of Youth Mentoring in an Urban Context: Adolescents' Perceptions of Relationship Styles
}

\author{
Regina Day Langhout, ${ }^{1}$ Jean E. Rhodes, ${ }^{2}$ and Lori N. Osborne ${ }^{3}$
}

Received January 30, 2003; revised April 17, 2003; accepted June 25, 2003

\begin{abstract}
The goal of this study was to empirically distinguish a range of mentor relationships and to evaluate their differential influence on adolescent outcomes. The study makes use of data that were collected as part of a national evaluation of Big Brothers/Big Sisters of America. The evaluation included 1138 youth, ranging in age from 10 through $16(M=12.25)$, who were assigned randomly to either a mentoring relationship or a control group and followed for 18 months. A series of analyses, based on the matched youth's accounts of the relationships, suggested 4 distinct types of relationships (i.e., moderate, unconditionally supportive, active, and low-key). The 4 groups tended to distinguish themselves from one another on the basis of perceived support, structure, and activity. Relative to the controls, youth who characterized their mentor relationships as providing moderate levels of both activity and structure and conditional support derived the largest number of benefits from the relationships. These included improvements in social, psychological, and academic outcomes. Implications of the findings for research and intervention are discussed.
\end{abstract}

KEY WORDS: youth mentoring; mentoring relationship styles.

Volunteer mentoring programs have been advocated increasingly in such diverse areas as welfare reform, education, violence prevention, school-to-work transition, and national service (Freedman, 1993; Rhodes, 2002). Approximately 2.5 million youth are involved in mentoring programs, including more than 10,000 matches in Big Brothers/Big Sisters nationwide (Rhodes, 2002). Evaluations of volunteer mentoring, paraprofessional, and

\footnotetext{
${ }^{1}$ Assistant Professor of Psychology at Wesleyan University, Middletown, Connecticut. Received $\mathrm{PhD}$ in clinical/community psychology from the University of Illinois at Urbana - Champaign. Major research interests currently include how schools inhibit or facilitate engagement and wellbeing. To whom correspondence should be addressed at Department of Psychology, Wesleyan University, Middletown, Connecticut, 06459; e-mail: rlanghout@wesleyan.edu.

${ }^{2}$ Professor of Psychology at the University of Massachusetts, Boston, Massachusetts. Received $\mathrm{PhD}$ in clinical/community psychology from DePaul University. Major research interests are youth mentoring and community intervention.

${ }^{3}$ Staff Therapist at Illinois Masonic Medical Center. Received PhD in clinical/community psychology from the University of Illinois at Urbana Champaign and is working with young children with behavior problems.
}

volunteer programs provide evidence of positive outcomes, including improvements in youth's self-concept and academic achievement (Linnehan, 2001; McPartland and Nettles, 1991), lower recidivism rates among juvenile delinquents (Davidson et al., 1987), and reductions in substance abuse (Aseltine et al., 2000; LoSciuto et al., 1996).

Additional evidence for the effectiveness of mentoring was provided by an impact study of Big Brothers/Big Sisters (Grossman and Tierney, 1998). Control youth were placed on a waiting list for 18 months and the experimental group youth were matched with mentors. The 2 groups were compared on a number of outcomes. Relative to control youth, matched participants reported skipping fewer days of school, lower levels of substance initiation and use, less physical aggression, higher scholastic competence, attendance, and grades. In addition to these behavioral and academic outcomes, mentoring relationships were associated with improvements in the youth's relationships with their parents and peers.

The results reported by Grossman and Tierney (1998) are consistent with results from a recent meta-analysis. DuBois et al. (2002) examined over 55 empirical studies 
of mentoring programs. Their findings indicate that there is a small but significant positive effect for mentees in the areas of enhanced psychological, social, academic, and job/employment functioning, as well as reductions in problem behaviors.

Although the findings provide evidence for the efficacy of mentoring interventions on a broad range of outcome variables, basic questions remain regarding the nature of the relationships. In particular, additional information is needed regarding the ways in which variations in mentors' stances affect different youth outcomes. Few studies, however, have tracked associations between youth and volunteers. Indeed, DuBois et al. (2002) were unable to reliably analyze relationship characteristics because of the lack of reported data.

Yet, it is possible to turn to a few studies that do discuss relational characteristics. Davidson and colleagues (Davidson et al., 1987; Mitchell et al., 1980), for example, observed associations between the strategies adopted by trained volunteers and the outcomes of youth in the juvenile court system. Those youth who had volunteers who were trained to be more structured and goal-oriented in their relationships with youth reported more positive outcomes. In another study, DuBois and Neville (1997) found associations between mentors' appraisals of relationships and youth outcomes, such that mentors' reports of closeness with their mentees were associated with youth benefits. Others have highlighted the ways in which differences in mentors' approaches relate to youth's satisfaction with their relationships. For example, Morrow and Styles (1995) conducted interviews with over 200 adolescents and found that mentoring relationships tended to fall into two broad categories, labeled developmental and prescriptive. Satisfied pairs-defined by feelings of liking, attachment to, and commonalty with the other members-were determined to be more developmental and youth-driven. Developmental pairs were considered reliable and trusting, enjoyable, and youth felt supported rather than judged. Prescriptive pairs, on the other hand, were characterized by adult-governed goals, no adjustment of expectations on the part of the adult, and a lack of consistent support from the adult.

Along similar lines, Sipe (1998) synthesized the literature on mentoring and concluded that successful mentors tended to be a steady and involved presence in the youth's lives, respecting the youth's viewpoints, and seeking supervision from support staff when needed. In addition, successful mentors respected youth's desire to have fun. This latter observation has also been made in debates regarding the relative importance of engaging youth in activities versus emotionally based conversations. For example, some researchers suggest that close relationships are more likely to emerge as the by-product of shared involvement in educational, athletic, or other activities. Darling et al. (1994), for example, have argued that mentors who engage with youth in challenging activities are more likely to be successful than those whose primary goal is to simply get to know the adolescent through a focus on conversations about goals, relationships, or problems. They note that emotional connections with nonparent adults appear to grow out of adults' validation of adolescents' effort and ability in activities. As they observed, "Ironically, relationships were built when building a relationship was not the main purpose of getting together" (p. 228).

Research from the counseling and parenting literature provide additional insights into the role of structure and support in helping relationships, and the various approaches that adults take when working with children and adolescents. In the counseling literature, Howard et al. (1986) have conceptualized psychotherapists as providing some combination of high or low support and high or low direction. They assert that one style is not necessarily indicative of a better therapeutic relationship than another. Rather, it is the clients' characteristics and readiness to change that should determine whether high/low direction and high/low support would best develop the therapeutic relationship. In other words, context should be taken into consideration when determining how to best work with the client.

Distinct parenting styles have also been identified, as determined by the relative emphasis that parents place on supportiveness and control (Baumrind, 1968, 1971; Holmbeck et al., 1995). Although parenting that is relatively high in both domains is generally considered to be most conducive to favorable developmental outcomes (Lamborn et al., 1991; Steinberg et al., 1995), others have emphasized the importance of considering the context of parenting, including social class and ethnicity (Arendell, 1997; Mason et al., 1994; Portes et al., 1986). For example, middle-class and upper-middle-class mothers grant more autonomy and equality, are less restrictive and punitive, and are more permissive and child-centered than working-class and working poor mothers (cf. HoffGinsberg and Tardiff, 1995; Jarrett, 1995, 1999). These comparisons should not be viewed as pointing to deficits, but should instead be viewed as evidence in the importance of context.

In addition to environmental mediators, it is also important to note age and developmental processes when considering parenting styles. Most of the mentees in this study are adolescents. Adolescence marks an important developmental change in parenting relationships, where children are beginning to rely less on parents and becoming more independent. Indeed, in a 3-year longitu- 
dinal study, van Wel et al. (2000) found that the bond between children and their parents is slightly, though significantly, less positive during early and midadolescence. Similarly, other studies have found that early to mid-aged adolescents perceive less support from their parents, and as this support decreases, self-reported general psychological well-being also decreases (Ben-Zur, 2003; Helsen et al., 2000; Laible et al., 2000).

The preceding discussion provides insights into the possible sources of variation in mentoring relationships and highlights the interactive nature of the bond. The major goal of this study was to distinguish empirically a range of mentoring relationships and to relate these systematically to mentee outcomes. On the basis of the findings cited above, we expected that structure, activity, and support would be distinguishing dimensions in mentor relationships. Further, on the basis of the helping and parenting literature, we hypothesize that relationships which mentees perceived as more structured would be associated with more positive social, psychological, academic, and behavioral outcomes. Although the focus of the analyses is on the mentees' characterizations of their mentors, it is our assumption that such characterizations are the product of mentor, mentee, and dyadic influences. ${ }^{4}$ Indeed, assigned mentoring relationships are constituted in response to multiple factors, including mentor and mentee backgrounds, characteristics, and interests, and reflect an interplay between individuals. A deeper understanding of this interplay and how it relates to youth outcomes can help to maximize the positive influences of mentoring relationships.

\section{METHOD}

\section{Participants}

This study makes use of data that were collected as part of the national evaluation of Big Brothers Big Sisters (BBBS; Grossman and Tierney, 1998), the largest and arguably most influential evaluation of mentoring to date. The evaluation included 1138 children, all of whom applied to BBBS programs in 1992 and 1993. The mentees ranged in age from 10 through $16(M=12.25$, $\mathrm{SD}=1.71)$. Sixty-two percent were boys, and $56.8 \%$ were members of minority groups (71\% African American, $18 \%$ Hispanic, $5 \%$ biracial, $3 \%$ Native American, and

\footnotetext{
${ }^{4}$ It would, of course, provide more information to have a more complete typology including parental and mentor perceptions, but because of missing and incomplete data, our sample size would have been too small to run reliable analyses if these data were integrated into the relationship styles.
}

$3 \%$ other); the other $43.2 \%$ identified as White. Eightythree percent were from families with total annual incomes of less than $\$ 25,000$ and over $40 \%$ were receiving food stamps and/or public assistance. Ninety percent of the youth lived with 1 parent and another 5\% lived with one of their grandparents.

With respect to mentors, the mean age was 30 , with a range of $18-58$. Most were White $(73 \%)$, with the next largest sizable group being Black/African American (21\%). A much smaller portion of the mentors identified as Latino/Hispanic (4\%), Asian/Asian American/Pacific Islander $(1.2 \%)$, biracial $(0.3 \%)$, or other $(0.6 \%)$. In terms of education, almost half of the mentors had a bachelor's degree $(47 \%)$, and almost one third had at least some college but less than a 4-year degree (32\%). A sizable number had a master's degree or PhD/JD/MD (14\%). The remaining (7\%) had a high school diploma or a GED. Finally, the large majority of mentors $(87 \%)$ worked fulltime, whereas a small number $(1.5 \%)$ worked part-time (the missing data here may indicate seasonal work or unemployment). All participants were treated in accordance with the American Psychological Association's Ethical Principles (American Psychological Association, 1992).

\section{Design and Procedure}

From the network of more than 500 BBBS local agencies, 8 agencies were selected to participate in the outcomes study. The key selection criteria for inclusion in the impact study were a large, active caseload and waiting list, and geographic diversity. With only a few exceptions, all of the youth who enrolled in the 8 selected BBBS agencies during the intake period (i.e., 12 months) were encouraged to participate in the research. Once a youth was informed about the study, determined to be eligible, and assented to participate (along with parent(s)' signed, informed consent), he or she was randomly assigned to either the experimental $(N=571)$ or control group $(N=567)$. Within the experimental group, 109 youth were not matched during the 18-month period. ${ }^{5}$ The control group was placed on an 18-month waiting list for a later match. Sixty-one potential participants were excluded from the study because they were under contractual obligation from child protective services or a youth-service organization. Thus, analyses were conducted with data from the 378 experimental

\footnotetext{
${ }^{5}$ Thirty-three of these youth were not matched because they became ineligible (e.g., parent remarried, youth was no longer in the eligible age range, or youth moved). Thirty-one participants declined a match, and 21 were not matched because a suitable volunteer was not found during the 18 -month period. The remaining 24 youth were not matched for a number of reasons, with the most common reason being that the parent did not follow through with the intake process.
} 
group youth who were matched with a volunteer and the 472 control group youth. Grossman and Tierney (1998) report no differences in the experimental group youth who were assigned versus not assigned to a mentor.

Agency staff matched particular adult volunteers with particular youth on the basis of a variety of factors. Although shared interest, reasonable geographic proximity, and same-race match preferences are made, most of the criteria in determining a match are subjective. All volunteers, however, underwent an intensive screening process, followed by agency-based training and case management. The average length of the relationships was 11.4 months, with dyads meeting an average of 3 times per month, $4 \mathrm{hr}$ each time. Over $77 \%$ of the youth met with their mentor one or more times per week. Dyads typically engaged in a wide variety of leisure- and goal-oriented discussions and activities with the overall goal of promoting the youth's positive development.

All participants were interviewed by telephone before they knew their experimental status; only $2.7 \%$ of the participants refused. Follow-up interviews were conducted 18 months later by telephone with the baseline participants. Baseline and follow-up interviews were completed with 959 youth or $84.3 \%$ of the sample.

\section{Measures}

Measures were selected to tap the general outcome domains of social, psychological, academic, and behavioral functioning. As earlier hypothesized, the relationships were expected to influence these areas.

\section{Social Functioning}

Parent Relationships. The Inventory of Parent and Peer Attachment (IPPA; Armsden and Greenberg, 1987) is a 23-item scale containing questions related to a child or an adolescent's relationship with his/her primary caregiver. Responses are coded on a 4-point scale, ranging from 1 ("hardly ever true") to 4 ("very often true"). IPPA contains 3 subscales: communication (e.g., my mother can tell when I am upset about something), trust (e.g., my father respects my feelings), and alienation (e.g., talking over problems with my mother makes me feel ashamed or foolish). Cronbach's $\alpha$ reliability coefficients of the subscales were $0.77,0.83$, and 0.76 , respectively.

Peer Support. The 20-item Features of Children's Friendship Scale (Berndt and Perry, 1986) consists of 5 subscales, each representing a different support or problem domain. Questions deal with the frequency of certain behaviors or interactions. All subscales are composed of
4 items and have a response scale from 1 ("hardly ever") to 4 ("pretty often"). The 5 subscales were intimacy, e.g., "do you talk to your friends about something that is bothering you?" $(\alpha=.66)$; emotional support, e.g., "do your friends praise or congratulate you when you do a good job on something?" $(\alpha=0.69)$; instrumental support, e.g., "would your friends agree to do a favor for you if you asked?" $(\alpha=0.73)$; conflict, e.g., "do your friends annoy or bug you?" ( $\alpha=0.66)$; and inequality, e.g., "do your friends try to boss you around?" $(\alpha=0.69)$.

Social Acceptance. Harter's Self-Perception Profile for Children's Social Acceptance subscale (1986) was used to assess youth's perceived social acceptance. The format of the scale consists of statements describing the behavior of 2 groups, and respondents are then asked to indicate whether they were more like the first or second group and whether the statement was "really true" or "sort of true" for them. An example item is "some kids would like to have a lot more friends/other kids have as many friends as they want." The $\alpha$ for this 6-item scale was 0.74 .

Psychological Functioning. Harter's (1986) 6-item Self-Worth subscale $(\alpha=0.75)$, which is also a part of the Self-Perception Profile for Children, follows the same format described above. A sample item is "Some kids are pretty pleased with themselves/other kids are often unhappy with themselves."

\section{Academic Functioning}

School Value. This 18-item measure (Berndt and Miller, 1986) assesses the extent to which respondents value academic success and the information that they learn in school, e.g., "do you care about doing your best at school?" On a 4-point scale, ranging from 1 ("hardly ever") to 4 ("pretty often"), respondents were asked to indicate the frequency with which they felt certain ways about school $(\alpha=0.86)$.

Grades. Participants were asked the question, "Which of the following best described your grades?" Responses fell along an 8-point scale, with 1 being mostly D's and F's and 8 being A's.

Scholastic Competence. Harter's (1986) 6-item subscale of scholastic competence $(\alpha=0.77)$ is part of the Self-Perception Profile for Children described above. Here, a sample item is "some kids feel that they are very good at their schoolwork/other kids worry about whether they can do the schoolwork assigned to them."

\section{Behavioral Functioning}

The final Harter (1986) 6-item subscale is behavioral conduct $(\alpha=0.76)$. An example item from this scale is 
Table I. Sample Items for Mentoring Relationship Scales

\begin{tabular}{|c|c|c|c|}
\hline Scale name & Sample item & \# Items & $\alpha$ \\
\hline Unconditional Support & $\begin{array}{l}\text { If } \mathrm{B}^{a} \text { found out I got a bad grade, he/she would say we couldn't } \\
\text { do anything fun until I did better }{ }^{b}\end{array}$ & 3 & 0.65 \\
\hline Relationship Satisfaction & Wish B knew me better ${ }^{b}$ & 6 & 0.79 \\
\hline Lack of Negative Affect & When I'm with..., I feel disappointed ${ }^{b}$ & 4 & 0.80 \\
\hline Positive Affect & When I'm with ..., I feel happy & 4 & 0.82 \\
\hline Self Esteem & B helps me see I'm good at things & 3 & 0.80 \\
\hline B doesn't try to "fix it" & $\begin{array}{l}\text { When something is bugging you, how often does B have lots of good } \\
\text { ideas about how to solve problems? }\end{array}$ & 3 & 0.78 \\
\hline Encouragement & If B found out I got a bad grade, he/she would tell me I will do better next time & 4 & 0.69 \\
\hline Social Skills & B helps me learn how to get along better with teachers & 2 & 0.70 \\
\hline Does not talk about goals & B talks about how far you'll go in school ${ }^{b}$ & 4 & 0.81 \\
\hline Does not talk about relationships & B talks about your relationship to parent ${ }^{b}$ & 5 & 0.73 \\
\hline No going out & We go to movies ${ }^{b}$ & 3 & 0.66 \\
\hline No educational/fun activities & We work on homework ${ }^{b}$ & 3 & 0.61 \\
\hline No domestic activities & We cook or bake $e^{b}$ & 4 & 0.61 \\
\hline No sports/games & We play sports ${ }^{b}$ & 3 & 0.64 \\
\hline
\end{tabular}

${ }^{a} \mathrm{~B}=$ Big brother/sister, and $\mathrm{L}=$ Little bother/sister. ${ }^{b}$ Item recoded.

"some kids usually act the way they are supposed to/other kids often don't act the way they are supposed to."

\section{Mentee's Relationship Perceptions}

Based on the earlier qualitative work of Morrow and Styles (1995), the follow-up interviews contained a series of questions that were administered to the intervention group regarding their relationships with their mentors. The questions were designed to assess the frequency and type of activities that the mentors participated in with their mentees and the youth's feelings toward and impressions of his or her mentor. An exploratory factor analysis performed by the agency responsible for the data collection suggested 15 mentoring relationship scales $(\mathrm{N}$. L. Resch, personal communication, 1997). To date, some of these scales have been used in other research articles (see Grossman and Rhodes, 2002). For consistency, we chose to retain the scales provided (see Table I for sample items and $\alpha$ ).

\section{RESULTS}

\section{Mentee's Perceptions of Relationship Characteristics}

To determine if mentee's perceived distinct and unique types of mentoring relationships, analyses proceeded in 3 steps: data reduction, confirmation of structure, and determination of perceptual relationship types. Steps 1 (data reduction) and 2 (confirmation) were inter- mediate steps that were necessary before Step 3 (relationship typologies) could be attempted.

\section{Data Reduction}

To facilitate and clarify interpretations, data reduction (Step 1) of the mentee's 15 mentoring relationships scales was employed. All relationship scales were recoded in the same direction because data for these procedures must be in the form of a similarity matrix. A random half sample of the data $(n=170)$ was submitted to an exploratory factor analysis with varimax rotation. Four factors were suggested, all of which had eigenvalues greater than 1 . One factor consisted of 1 scale with a high loading (Mentee-Centered or L-Centered Activities). This scale was dropped and the factor analysis was rerun, this time yielding a 3 -factor solution, which accounted for $54 \%$ of the variance. No scales double-loaded on any factors with loadings of 0.30 or higher.

\section{Verification of Data Reduction}

To minimize the possibility of chance findings, the resulting structure was verified (Step 2) via confirmatory factor analysis as implemented by LISREL 8 (Jöreskog et al., 2001) on the second half-sample $(n=157)$. Fit indicies suggested an acceptable fit of the data $\left(\chi^{2}=\right.$ $163.23, \mathrm{df}=74 ; \chi^{2} / \mathrm{df}=2.21$; Root-Mean-Square Residual $=0.084 ;$ Standardized Root-Mean-Square Residual $=$ 0.084; Goodness of Fit Index $=0.87$; Adjusted Goodness of Fit Index $=0.81$; Normed Fit Index $=0.77$; NonNormed Fit Index $=0.83$ ). See Table II for a correlation 
Table II. Correlation Matrix for Mentoring Relationship Scales

\begin{tabular}{|c|c|c|c|c|c|c|c|c|c|c|c|c|c|c|c|}
\hline & L-C & $\mathrm{Sat}^{a}$ & Soc. & S.E. & Enc & U.S. ${ }^{a}$ & Pos & $\mathrm{No}^{a}$ & $\mathrm{~N}-\mathrm{G}^{a}$ & $\mathrm{~N}-\mathrm{R}^{a}$ & $\mathrm{~N}-\mathrm{O}^{a}$ & $\mathrm{~N}-\mathrm{E}^{a}$ & $\mathrm{~N}-\mathrm{D}^{a}$ & $\mathrm{~N}-\mathrm{S}^{a}$ & $\mathrm{~N}-\mathrm{F}^{a}$ \\
\hline L-C & 1.0 & & & & & & & & & & & & & & \\
\hline Sat & $0.42^{*}$ & 1.0 & & & & & & & & & & & & & \\
\hline Soc & $0.38^{*}$ & 0.00 & 1.0 & & & & & & & & & & & & \\
\hline S.E. & $0.52^{*}$ & $0.28^{*}$ & $0.37^{*}$ & 1.0 & & & & & & & & & & & \\
\hline Enc & $0.49^{*}$ & $0.20^{*}$ & $0.42^{*}$ & $0.41^{*}$ & 1.0 & & & & & & & & & & \\
\hline U.S. & $0.18^{*}$ & $0.37^{*}$ & -0.08 & 0.09 & -0.07 & 1.0 & & & & & & & & & \\
\hline Pos & $0.55^{*}$ & $0.22^{*}$ & $0.46^{*}$ & $0.51^{*}$ & $0.45^{*}$ & 0.04 & 1.0 & & & & & & & & \\
\hline No & $0.53^{*}$ & $0.62^{*}$ & $0.13^{*}$ & $0.37^{*}$ & $0.25^{*}$ & $0.34^{*}$ & $0.35^{*}$ & 1.0 & & & & & & & \\
\hline N-G & $0.43^{*}$ & $0.19^{*}$ & $0.45^{*}$ & $0.35^{*}$ & $0.40^{*}$ & -0.06 & $0.33^{*}$ & $0.20^{*}$ & 1.0 & & & & & & \\
\hline N-R & $0.33^{*}$ & -0.04 & $0.34^{*}$ & $0.28^{*}$ & $0.22^{*}$ & -0.10 & $0.29^{*}$ & 0.06 & $0.44^{*}$ & 1.0 & & & & & \\
\hline $\mathrm{N}-\mathrm{O}$ & $0.37^{*}$ & $0.15^{*}$ & $0.21^{*}$ & $0.28^{*}$ & $0.23^{*}$ & 0.05 & $0.31^{*}$ & $0.18^{*}$ & $0.33^{*}$ & $0.31^{*}$ & 1.0 & & & & \\
\hline N-E & $0.29^{*}$ & 0.04 & $0.30^{*}$ & $0.29^{*}$ & $0.24^{*}$ & -0.06 & $0.25^{*}$ & $0.11^{*}$ & $0.35^{*}$ & $0.29^{*}$ & $0.34^{*}$ & 1.0 & & & \\
\hline N-D & $0.26^{*}$ & -0.05 & $0.20^{*}$ & $0.26^{*}$ & $0.14^{*}$ & $-0.18^{*}$ & $0.26^{*}$ & 0.05 & $0.25^{*}$ & $0.34^{*}$ & $0.38^{*}$ & $0.42^{*}$ & 1.0 & & \\
\hline $\mathrm{N}-\mathrm{S}$ & $0.34^{*}$ & 0.02 & $0.24^{*}$ & $0.29^{*}$ & $0.17^{*}$ & -0.07 & $0.29^{*}$ & $0.13^{*}$ & $0.27^{*}$ & $0.22^{*}$ & $0.31^{*}$ & $0.38^{*}$ & $0.36^{*}$ & 1.0 & \\
\hline $\mathrm{N}-\mathrm{F}$ & $0.50^{*}$ & $0.30^{*}$ & $0.42^{*}$ & $0.53^{*}$ & $0.44^{*}$ & 0.09 & $0.50^{*}$ & $0.33^{*}$ & $0.51^{*}$ & $0.40^{*}$ & $0.36^{*}$ & $0.32^{*}$ & $0.30^{*}$ & $0.26^{*}$ & 1.0 \\
\hline
\end{tabular}

Note. L-C, Little-Centered Activities; Sat, Satisfaction with the Relationship; Soc, Social Skills; S.E., Self Esteem; Enc, Encouragement; U.S., Unconditional Support; Pos, Positive Affect; No, Lack of Negative Affect; N-G, B does not talk about goals; N-R, B does not talk about Relationships; N-O, No going out; N-E, No educational/fun activities; N-D, No domestic activities; N-S, No sports/activities; N-F, B does not try to fix it.

${ }^{a}$ Scale was reverse coded to yield a mostly positive correlation matrix.

${ }^{*} p<0.01$.

matrix of all of the mentoring relationship scales and Table III for factor loadings.

Participants' responses on the scales fell into 3 overall latent categories, which we have labeled Unstructured, Low Activity, and Supportive. The Unstructured category was characterized by general positive affect, but relatively little emphasis on talking about relationships, goals, or problems. Low levels of participation in the following activities determined the Low Activity category: going out for general entertainment, educational activities or

Table III. Confirmatory Factor Analysis Solution

\begin{tabular}{lccc}
\hline \multicolumn{1}{c}{ Scale } & Support & $\begin{array}{c}\text { Unstructured } \\
\text { style }\end{array}$ & $\begin{array}{c}\text { Low } \\
\text { activity }\end{array}$ \\
\hline Relationship Satisfaction & 0.68 & & \\
Lack of Negative Affect & 0.93 & & \\
Unconditional Support & 0.43 & & \\
Positive Affect & & 0.74 & \\
Self Esteem & & 0.75 & \\
B does not try to "fix it" & & 0.75 & \\
Encouragement & & 0.48 & \\
Social Skills & 0.54 & \\
Does not talk about goals & & 0.56 & \\
Does not talk about & & 0.38 & \\
$\quad$ relationships & & & \\
No educational/ & & \\
$\quad$ fun activities & & & 0.62 \\
No going out & & & 0.62 \\
No domestic activities & & & 0.62 \\
No sports/games & & & \\
\hline
\end{tabular}

fun, domestic-related activities, or sports and games. Finally, the Support category included the following scales: unconditional support, satisfaction with the relationship, and lack of negative affect. Overall, these results nicely parallel the mentoring, parenting, and counseling literatures. For the sake of clarity and consistency with the parenting and counseling literature, the Unstructured and Low Activity categories were recoded so that higher scores were Structured and Activity-Based, and will be referred to as such throughout the rest of the text. Recoding these scales has no effect on the categories. Parental appraisals of the mentor relationships paralleled the youth's perceptions of relationships, ${ }^{6}$ providing an additional validity check, but were not included in these analyses because of missing data.

\section{Mentee's Perceptions of Relational Typologies}

The third and final step was to determine specific relational typologies. A $k$-means cluster analysis was

\footnotetext{
${ }^{6}$ The parent scales consisted of the parent's perception that the mentor relationship was youth-centered and that the mentor made an effort with the youth. These scales most closely map onto the youth's support cluster. Indeed, the correlation between the mentee support cluster and the parent cluster is significant, $r=0.32, p<0.01$. For each relationship type, the combined parent scales and mentee support cluster $z$-scores were, respectively, -0.17 and -0.80 (moderate); 0.25 and 0.93 (unconditionally supportive); -0.87 and -0.40 (active); and 0.91 and 0.62 (low-key).
} 


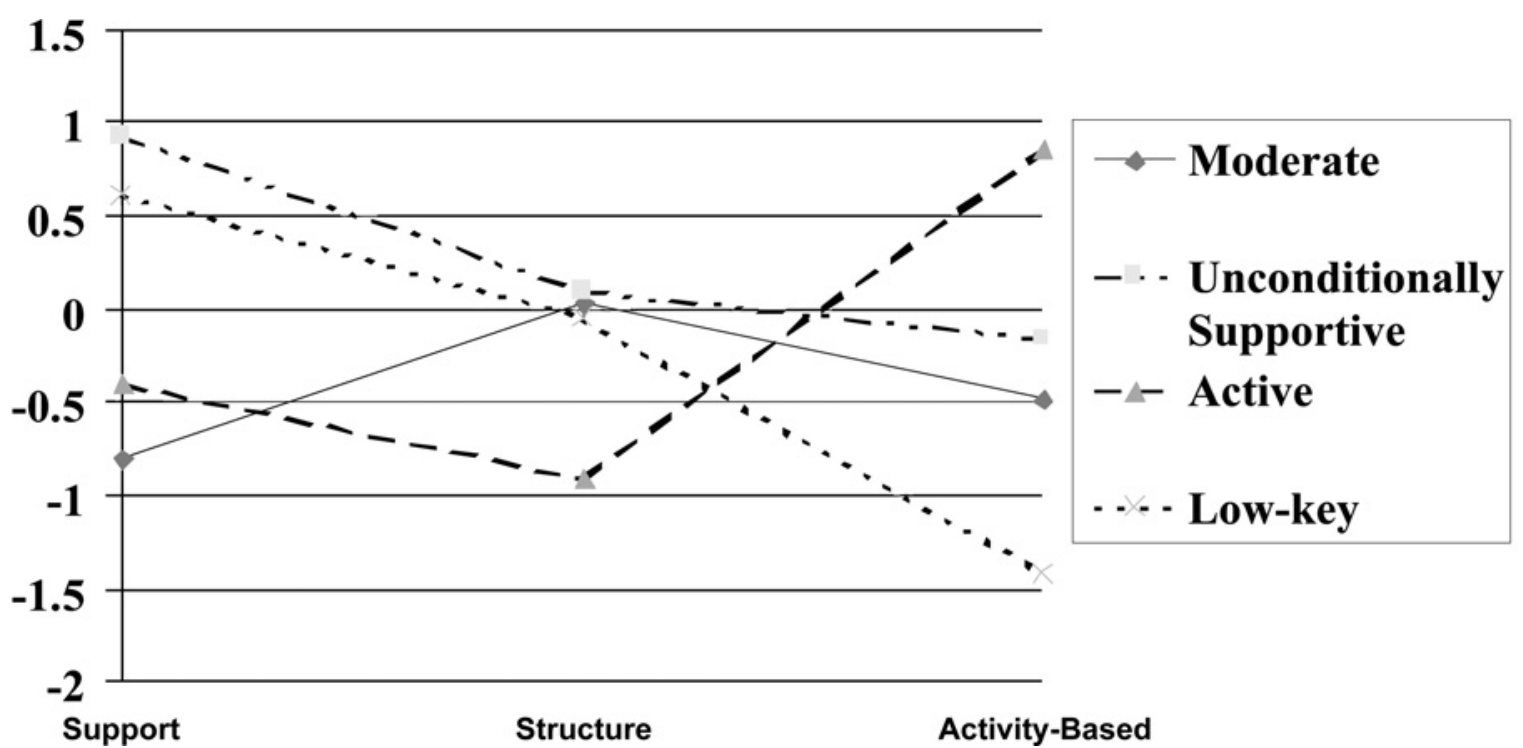

Fig. 1. Mentoring relationship profiles based on $k$-means cluster solution.

performed, which examined each youth individually on the basis of their scale scores. $k$-Means clustering is a nonhierarchical data analysis technique that uses an algorithm to suggest groupings in such a way as to maximize between group contrasts (Wilkinson et al., 1996). An advantage of this procedure is that clusters are not merged in a stepwise fashion. Rather, the algorithm attempts to separate the profiles by examining the distances among all of the objects (in this case, the experimental group youth). Four groups were selected for the final $k$-means solution, which were distinguished on the basis of youth's satisfaction with the relationship and the level of support, structure, and activity they felt that the mentor provided (see Fig. 1). Variable profiles were created by z-scoring all of the scales separately, and then summing across scales within the clusters, so that each scale would be equally weighted in determining the cluster score and profile. Finally, cluster scores were converted into $z$-scores so that all clusters were on the same metric and thus could be compared.

On the basis of the variable profiles, the mentor groups were characterized in terms of support and structure as follows: Group 1, "moderate" $(n=112)$; Group 2, "unconditionally supportive" ( $n=69)$; Group 3, "active" $(n=104)$; and Group 4, "low-key" $(n=42)$. Somewhat lower levels of positive support relative to the other groups characterized the "moderate" group. Youth in this group participated in moderate levels of structured conversations around goals and in slightly fewer activities with their mentors than did other groups. The "supportive" group reported moderate levels of structure and activity and perceived higher levels of support than did the "unconditionally supportive" group. The "active" group, on the other hand, reported the lowest levels of structure with their mentors but the highest levels of participation in activities. Finally, the "low-key" group ranked relatively high on levels of support and reported moderate structure, but participated in relatively few activities.

\section{Perceived Relationship Group Differences}

\section{Differences in Groups at Time 1}

Few differences emerged at Time 1 for any of the outcomes variables. With respect to social functioning, there were no differences in youth's perceptions of their relationships with their parents, or in terms of social acceptance. Psychological and behavioral functioning also showed no differences at Time 1.

Differences did emerge for mentee's perceptions of their peer relationships, a social functioning indicator, at Time 1. MANOVA results were significant (Wilks' $\Lambda=0.96, p<0.05$ ) and indicated that two scales, conflict and intimacy, were different at Time $1 \quad(F(4,878)=2.94, p<0.05$; $F(4,878)=2.87, p<0.05, \quad$ respectively $). \quad$ There were no differences between the relationship types and the control group for conflict at Time 1. Rather, the significant difference was between the "moderate" and 
"unconditionally supportive" groups, with the former group indicating higher levels of peer conflict $(M=11.68, \mathrm{SD}=3.13)$ than the latter $(M=10.24, \mathrm{SD}=3.13)$. With respect to intimacy, the "active" group had higher scores than did the control group at Time $1(M=11.77, \mathrm{SD}=2.62$, and $M=10.75, \mathrm{SD}=3.18$, respectively).

There were marginal differences in Time 1 scores for youth's perceptions of their academic outcomes (MANOVA Wilks's $\Lambda=0.95, p=0.16$ ). ANOVA results indicated that the difference at Time 1 was due to the school value scale $(F(4,852)=2.62, p<0.05)$, but not the school competency scale or perceived grades. Here, the only significant difference was between the "active" and "low-key" groups, with the former group placing more emphasis on the value of school $(M=58.06, \mathrm{SD}=$ 6.76) than the latter $(M=54.20, \mathrm{SD}=7.30)$ at Time 1.

\section{Demographic Characteristics}

The relationship groups did not differ as a function of the mentors' age, gender, ethnicity (when comparing African American/Black and European American/White), total annual income, highest grade completed, marital status, single parent upbringing, work status (full- or parttime), experience as a big brother/big sister, or experience as a mentee. Additionally, there were no differences among mentoring relationship groups based on the youth's gender, ethnicity, family income level, or parent education. All tests were 2-tailed. Because many of the comparisons were based on mentor information, these comparisons can only be between groups who were assigned a mentor.

Finally, a loglinear regression was performed to determine whether Time 1 outcome variables (i.e., social, psychological, academic, and behavioral indices), mentee and mentee family variables (i.e., mentee gender, ethnicity, family income, parent occupation, and education), mentor demographic variables (i.e., mentor gender, ethnicity, age, occupation, income, education, work status [full- or part-time], been a mentor previously, been a mentee previously, and single- or 2-parent upbringing), and the length of the match could predict Time 2 relationship characteristics. Pearson $\chi^{2}$ equaled 60.04 with 114 degrees of freedom $(n=154)$. Although the $\chi^{2} /$ df ratio was less than 1, indicating a good fit for the model, none of the individual predictors had significant estimates, ranging from $p=0.13$ to 0.96 . Overall, it appears that none of the Time 1 variables, mentee or mentor demographics, or length of the match are adequate predictors of mentor/mentee profiles at Time 2.

\section{Differences in Outcome Variables Based on Relationship Groups}

To test the hypothesis that more structured relationships lead to more positive social, psychological, academic, and behavioral outcomes, a series of multivariate analysis of covariance (MANCOVA) was performed for variables with no differences at Time 1. MANCOVA allows us to control for Time 1 levels of the variables. If MANCOVA was significant, contrasts were made between each mentoring group and the control group. By definition, variables with differences at Time 1 did not meet MANCOVA assumptions. In these cases, repeated measures split-plots were analyzed. All contrasts employed a Bonferroni correction to maintain a 0.05 significance level. Several differences emerged among the various mentor groups and the control group at Time 2 .

\section{Social Functioning}

\section{Parent Relationships}

As mentioned previously, pretest IPPA scores (via MANOVA) showed no differences at Time 1, an assumption for MANCOVA. MANCOVA results indicated there was a difference in IPPA Time 2 scores after controlling for Time 1 scores (Wilks' $\Lambda=0.966, p<0.05$ ). An analysis of covariance (ANCOVA) indicated that the difference was in the parental alienation subscale $(F(4,838)=$ 3.686, $p<0.05)$. Significant contrasts revealed that, compared with the control group, the "moderate" group reported decreased alienation whereas the "unconditionally supportive" group reported increased parental alienation (see Table IV for adjusted means, standard deviations, and effect sizes, when appropriate).

Table IV. Adjusted Means (Standard Errors; Effect Sizes [for Significant Differences]) for IPPA Scores

\begin{tabular}{lccl}
\hline \multicolumn{1}{c}{ Clusters } & Trust & Communication & \multicolumn{1}{c}{ Alienation } \\
\hline Moderate & $31.92(0.40)$ & $28.86(0.43)$ & $21.47^{*}(0.43 ; 0.23)$ \\
Unconditionally & $31.61(0.51)$ & $28.42(0.55)$ & $19.05^{*}(0.55 ; 0.25)$ \\
$\quad$ supportive & & & \\
Active & $31.50(0.41)$ & $28.76(0.44)$ & $21.12(0.45)$ \\
Low-key & $31.79(0.64)$ & $28.93(0.69)$ & $19.82(0.70)$ \\
Control & $31.30(0.18)$ & $27.97(0.19)$ & $20.43(0.19)$ \\
Overall & $31.62(0.20)$ & $28.59(0.22)$ & $20.38(0.22)$ \\
\hline
\end{tabular}

Note. Tukey's 95\% confidence interval was applied; an asterisk indicates significant difference from the control group; ${ }^{*} p<0.05$. 
Table V. Adjusted Means (Standard Errors; Effect Sizes [When Significant]) for Features of Children's Friendships

\begin{tabular}{|c|c|c|c|c|c|}
\hline Relationship type & Inequality & Conflict & Intimacy & Emot. Support & Instrum. Support \\
\hline Moderate & $12.48^{*}(0.24 ; 0.31)$ & $12.03 *(0.24 ; 0.24)$ & $10.98(0.25)$ & $12.80(0.23)$ & $12.95(0.21)$ \\
\hline Unconditionally supportive & $11.09(0.31)$ & $10.29(0.31)$ & $11.04(0.32)$ & $12.12(0.30)$ & $12.74(0.27)$ \\
\hline Active & $11.59(0.25)$ & $11.47(0.24)$ & $12.01 *(0.25 ; 0.24)$ & $13.10^{*}(0.24 ; 0.27)$ & $13.32(0.21)$ \\
\hline Low-key & $12.75^{*}(0.38 ; 0.39)$ & $11.71^{*}(0.38 ; 0.22)$ & $10.98^{*}(0.40 ; 0.20)$ & $11.92 *(0.37 ; 0.25)$ & $12.55^{*}(0.33 ; 0.29)$ \\
\hline Control & $11.71(0.11)$ & $11.21(0.11)$ & $10.99(0.11)$ & $12.42(0.10)$ & $12.73(0.09)$ \\
\hline Overall & $11.92(0.12)$ & $11.34(0.12)$ & $11.20(0.13)$ & $12.47(0.12)$ & $12.86(0.11)$ \\
\hline
\end{tabular}

Note. Tukey’s $95 \%$ confidence interval was applied. An asterisk indicates significant difference from the control group; ${ }^{*} p<0.05$.

\section{Peer Support}

As shown earlier, the assumption of no differences at Time 1 was not met for the peer scales. Because of these Time 1 differences, a repeated measures split-plot was analyzed. With respect to the between-subject design, there was an effect for relationship groups (Wilks' $\Lambda=0.94, p<0.05$ ) such that the following peer scales were different by group: conflict $(F(4,861)=5.72, p<$ $0.05)$, inequality $(F(4,861)=5.21, p<0.05)$, intimacy $(F(4,861)=3.52, p<0.05)$, and emotional support $(F(4,861)=3.21, p<0.05)$. When compared to the control group, the "moderate" group reported decreased levels of conflict, and the "unconditionally supportive" group reported slight increases in conflict scores over time. Both the "moderate" and the "low-key" groups showed decreased levels of inequality compared to the control group. Examination of the intimacy scale indicated that the "active" group had elevated scores compared to the control group. Finally, emotional support scores were higher for the "active" group than for the control group (see Table V for means, standard deviations, and effect sizes, where appropriate).

\section{Social Acceptance}

ANOVA results indicated no differences in social acceptance at Time 1 or Time 2.

To summarize results related to social functioning, the participants in the "low-key" group perceived relatively lower levels of conflict and inequality with their peers over time. The "active" group seemed to move toward their peers over time. They perceived increases in emotional support and intimacy relative to the controls. The "moderate" group perceived decreased alienation from their parents, and less strain with their peers (based on their conflict and inequality scores) relative to the controls. The "unconditionally supportive" group perceived more conflict with their parents (based on alienation scores) relative to the controls, and less conflict with their peers.

\section{Psychological Functioning}

ANOVA results indicated no differences in selfworth scores at Time 1 . ANCOVA results indicated a difference at Time $2(F(4,796)=2.86, p<0.05)$, with the "moderate" group improving $(M=19.93, \mathrm{SD}=3.97)$ compared to the control group $(M=18.77, \mathrm{SD}=4.34$; effect size $=0.23$ ).

\section{Academic Functioning}

Because of the Time 1 trend toward differences as described earlier, school value, school competency, and perceived grades were analyzed separately.

\section{School Value}

Given the differences in Time 1 school value scores, a repeated measures ANOVA was performed on this variable. This indicated differences in Time 2 versus Time 1 school value, when averaged across the relationship clusters $(F(1,656)=4.70, p<0.05)$, and a difference among the relationship clusters when averaged over the 2 time points $(F(4,656)=4.91, p<0.05)$; however, no interaction was found between relationships clusters and school value over time. Thus, there was no indication that any particular relationship cluster was associated with better outcomes in school value than the controls.

\section{Scholastic Competence}

Univariate analyses of Time 1 perceived school competence failed to indicate differences by relationship cluster on this variable. ANCOVA results indicated that there was a significant difference in perceived school competence at Time 2, when controlling for Time $1(F(4,789)=$ $3.18, p<0.05)$. Significant contrasts revealed that both the "moderate" group $(M=17.54, \mathrm{SD}=4.21)$ and "active" group $(M=17.27, \mathrm{SD}=4.37)$ improved relative to the control group $(M=16.38, \mathrm{SD}=4.73$; effect size 
for moderate comparison $=0.19$, effect size for active comparison $=0.07$ ).

\section{Grades}

Finally, self-reported grades were examined. A univariate analysis showed no difference by relationship type at Time 1. ANCOVA results, with Time 1 as the covariate, showed no differences by relationship type for Time 2 self-reported grades.

\section{Behavioral Functioning}

A univariate analyses of Time 1 behavioral conduct scores indicated that there were no differences by relationship cluster on this variable, and ANCOVA analyses indicated no differences by relationship cluster at Time 2 , when controlling for Time 1 .

To summarize, mentees who perceive their relationships as "moderate," or moderately supportive, structured, and high in activity seem to be fairing the best with respect to psychological, school, parent, and peer outcomes. Those in the "active" group, who characterize their relationships in terms of a high level of activity, are also doing well in terms of school and peer relationships at time 2. The low-key group, who experience their mentor relationships as relatively high support and structure but low in activity, report less peer conflict at time 2-also a positive outcome. The unconditionally supportive group, who characterize their mentors as providing high levels of unconditional support, however, experience more parent alienation at Time 2 (see Fig. 2 for a summary of all Time 2 group differences).

\section{Alternative Hypothesis}

Differences in outcomes among the relationship groups may be accounted for by differences in duration of the mentoring relationship. One might argue that the longer the match, the more beneficial the outcomes. Indeed, Sipe (1998) and McKenna (1998) have reported relations between duration and outcomes. To determine whether the length of the match (measured in days) was different by mentoring group, a regression predicting duration of the match from perceived mentee typology (with typology group dummy coded) was conducted. Results indicated a significant difference in duration $(F(3,322)=$ $14.66, p<0.05)$, with the "active" group experiencing longer matches than the other 3 groups. The equation explained $11 \%$ of the variance of the length of the match.

An alternative hypothesis to explain group differences on outcomes measures, however, is that there is only one type of mentoring relationship and that relationship progresses through many stages so that typologies represent stages in the relationship. To test this hypothesis, beginning dates of the matches were examined. If relationship types had staggered beginning dates, then it would be more plausible to assume that differences were based on the progression of the mentoring relationship. If this hypothesis were true, it may be that, within a few additional months, the "permissive" group might also show more positive outcomes due to the mentoring relationship reaching another stage. On the other hand, if the differences in relationship types were not associated with the beginning dates, then our original hypothesis that the mentoring relationships are actually distinct would gain support; differences in relationship length would be based on mentors, mentees, or parents terminating the relationship rather than the relationships starting later (due to when

\begin{tabular}{|c|c|c|c|}
\hline Moderate & $\begin{array}{l}\text { Unconditionally } \\
\text { Supportive }\end{array}$ & Active & Low-key \\
\hline $\begin{array}{ll}\uparrow & \text { self-worth } \\
\downarrow & \text { school competence } \\
\downarrow & \text { alienation } \\
\downarrow & \text { inequality } \\
\downarrow & \text { conflict }\end{array}$ & $\uparrow$ alienation & $\begin{array}{ll}\boldsymbol{\uparrow} & \text { emotional } \\
\boldsymbol{\uparrow} & \text { intimacy } \\
\boldsymbol{\uparrow} & \text { school competence }\end{array}$ & $\begin{array}{ll}\downarrow & \text { conflict } \\
\Downarrow & \text { inequality }\end{array}$ \\
\hline
\end{tabular}

Fig. 2. Summary of outcomes based on mentoring relationships. 
matches occur) and thus being in an earlier stage. Consistent with the original hypothesis, differences in relationship length were due to staggered ending times rather than beginning times.

\section{DISCUSSION}

The findings presented in this study represent a beginning step toward empirically distinguishing a range of relationships and evaluating their differential influence on youth outcomes. A series of analyses, based on adolescent accounts of the relationships, suggested 4 types of mentoring relationships that tended to distinguish themselves on the basis of the level of the youth's perceived relationship support, structure, and activity.

The relationship types paralleled previous typologies of therapy and parenting styles, which also have tended to differentiate themselves along the dimensions of activity, structure, and support. The youth in the "active" group engaged in more activities than did the other groups, and perceived the lowest levels of structured conversation and problem solving. Relative to youth in the control group, participants in this group reported improvements in peer emotional support and intimacy as well as increased school competence. Consistent with previous work, these positive findings suggest that involvement in activities may facilitate relationship formation and expose youth to new arenas for competence building. As Sipe (1998, p. 16) concluded, "Not only is having fun a key part of relationship-building, but it provides youth with opportunities that are often not otherwise available to them."

It is also possible that high levels of activities are a proxy for higher levels of mentor investment in the relationship, as outings imply planning and a relatively larger time commitment than conversations. Additionally, positive changes in perceptions of scholastic competence suggest that, at least to some extent, the high level of structure may have centered on academic activities. Finally, although mentees perceive that the mentors may not have offered particularly high levels of unconditional support, they may have encouraged youth to seek emotional support from prosocial peers.

Youth in the "low-key" group, on the other hand, reported the lowest levels of involvement in activities. Although members of this group reported relatively positive feelings toward their mentors, there were only two differences-lower levels of peer inequality and conflict-in this group when compared to the control group. Even in the context of providing support and focusing on goals, mentors who fail to recognize adolescents' desire to engage in activities may be missing important opportunities for relationship building and enrichment. It is also quite possible that participation in fewer activities is indicative of lower overall levels of involvement in the relationship.

Participants who characterized their relationships in terms of "moderate" levels of activity and structure reported the largest number of benefits, including decreased alienation from parents, decreased conflict and inequality with friends, and an improved sense of self-worth and school competence relative to the controls. Interestingly, participants in this group rated their mentors as somewhat lower on the support dimension, implying that they were less satisfied, derived less unconditional support, and encountered relatively more negative affect. Such mentors may share certain similarities with authoritative parents who provide opportunities for enjoyable shared activities and set high standards, but do not offer unconditional support or avoid conflict (Steinberg et al., 1995). As such, higher levels of negative affect and conditional support in the mentoring relationships may not be necessarily problematic, as it may imply open and honest communication around important issues. Indeed conflict, and its successful resolution, can help individuals understand their differences and move forward toward goals (Jordan, 1991). Similarly, Luescher and Pillemer (1998) have argued that close intergenerational relationships are often laced with tension and conflict. They describe the ambivalence that characterizes such relations, wherein needs for autonomy or self-fulfillment can conflict with needs for closeness or help.

Perhaps surprisingly, youth in the "unconditionally supportive" group, who characterized their relationships as high in unconditional support and low in negative affect, while being moderate in structure and activities, shared none of these benefits and actually reported an increase in parental alienation. It may be the case that, rather than bolstering their capacity to derive support and intimacy from parents, mentors who were perceived as taking a more accepting, permissive approach competed directly with, and even supplanted, the youth's close relationships. It may also be the case that these mentors were adults who did not provide critical feedback to children, thus making it appear that other adult feedback was unwarranted.

The present findings have potential implications for both the training and the selection of volunteer mentors for youth. For example, it appears that adult mentors should be trained to be less like peers and more like good parents. Indeed, mentors who are perceived as providing high levels of unconditional support may actually have the effect of undermining the youth's extant relationships. The present findings suggest instead that positive outcomes are more likely to emerge when mentors engage in moderate 
levels of activity and impose some degree of structure and expectation. In other words, it appears that mentoring relationships characterized by structure, activity, and expectations (i.e., conditional support) are more beneficial than mentoring relationships characterized by little structure, low activity, and unconditional support. These findings parallel those of Davidson and colleagues (Davidson et al., 1987; Mitchell et al., 1980), who also noted that when volunteers provided some degree of structure (e.g., contracting with the youth, family, and others in the support network, taking an advocacy approach, and understanding problems from an ecological-transactional perspective), volunteers felt more positive about themselves and made an impact at multiple levels of the youth's lives.

The pattern of findings may reflect the needs and circumstances of the mentees, many of whom were living in low-income, urban settings. Different circumstances give rise to different needs, and a mentors stance should reflect those needs. Although it is important to consider the unique characteristics of each youth, mentor trainings should also reflect the characteristics, strengths, and constrains of the youth's setting. Additional training and supervision should be provided to familiarize mentors with the challenges imposed by low-income, urban settings, the potential risks of taking an unconditionally supportive stance, the need for adequate structure in relationships, and the strengths to build from with their mentees.

Within this context, recruitment efforts should be geared toward adults who are familiar with and are sensitive to these constraints. These adults may be found in local churches or community centers. Such efforts may result in relationships that provide additional support to the parents in such settings and more appropriately address the developmental needs of adolescents.

If mentors are to be trained to be more like a good parent, then they should be made familiar with the developmental literature on adolescent-parent relationships. The mentor can plan for the predictable developmental stage in early and midadolescence where the adolescent moves away from the parent and toward greater autonomy and independence (Ben-Zur, 2003; Helsen et al., 2000; Laible et al., 2000). The mentor can then view this transition as normal and continue to engage the mentee instead of viewing it as indicative of disinterest. Continued engagement will help the adolescent through this often difficult transition.

In addition to considering the context when designing the training, it is also important to consider what constitutes success. If, as was the case in Styles and Morrow's (1992) study of mentoring relationships, success is defined in terms of mentees' positive feelings toward mentors, then less conditional support and less structure are paramount. If, on the other hand, success is defined in terms of social, psychological, and/or academic outcomes, then a more structured approach appears to be beneficial. Being clear up front about the goals of the mentoring relationship should help guide how mentors are trained to be effective in reaching those goals.

Several limitations of the present research should be noted. Although the findings provide support for distinct types of mentoring relationships, the possibility remains that the groups actually represent phases in the course of mentoring relationships. Findings regarding relationship progression did not lend support to this alternative, but an investigation of mentoring relationships over a longer period of time would address the possibility more definitively. Additionally, the relationships were all situated within the context of a single mentoring organization serving adolescents in urban areas and may not be applicable to other types of programs (e.g., schoolbased) or with different-aged mentees. Additionally, the assessments of mentoring relationships and parent and peer relationships were based solely on the youth's perceptions. Because of their age, the participants may have been limited in their ability to engage in retrospective assessments of their mentor relationships and/or inhibited in their willingness to report personal or relationship difficulties. In particular, participants may have feared that negative appraisals would have jeopardized their relationships or their mentors' reputation within the program. Converging impressions from additional sources would have provided a more comprehensive picture of the relationships. An anonymous pencil-and-paper measure may have also provided an opportunity for youth to voice less positive perceptions of their relationships.

In the absence of such data, the possibility remains that the 4 groups were not differentiated on the basis of mentor-mentee relationship characteristics, but on the basis of youth characteristics. For example, on the basis of their prior experiences in relationships, certain youth may have been more likely to perceive their mentors as low in acceptance irrespective of the mentors' actual behavior. Inherent negative (or positive) perceptions of relationships, however, would not fully explain the inverse pattern of appraisals that emerged in this study (i.e., positive appraisals of mentors tended to be associated with negative appraisals of parents/peers). Additionally, parent perceptions of the mentor-mentee relationships corresponded with the mentees' perceptions. Nonetheless, information regarding the characteristics of the youth at the time of the their entry into the program should be more fully integrated into subsequent studies. In addition to the youth's descriptions of their mentors, all of the dependent variables in this study were based on self-reports. Although 
perceptions of social, psychological, academic, and behavioral functioning are important dimensions of adolescent adjustment (Harter, 1985), future studies should include additional measures of adjustment and gather data from other sources.

Finally, it is important to note that the contrasts of the mentoring groups (individually and collectively) with the control group yielded relatively modest effect sizes $(0.07-$ 0.39 ). These results are consistent with the meta-analysis results reported by DuBois et al. (2002). Mentoring relationships are associated with significant but modest positive outcomes. Thus, although potentially helpful in some respects, we should remain mindful of the limitations of mentoring relationships and resist policy makers' attempts to substitute volunteer efforts for sustained public investment in youth.

With these caveats in mind, the results of this study do shed light onto the process of mentoring and the various styles that are employed by volunteers. Currently, caseworkers and program personnel use available information as well as their own experienced-based intuition to make their best estimates of a potential volunteer's suitability, training needs, and "fit" with particular youth. Although such judgment calls remain important, the added identification of relationship typologies might provide additional information for the refinement of mentoring programs.

\section{ACKNOWLEDGMENTS}

This paper is based on the master's thesis of the first author. This research was supported by a grant from the William T. Grant Foundation, and partially supported by an NIMH, National Research Service Award, No. MH14257, to the University of Illinois. The research was conducted while the first author was a predoctoral trainee in the Quantitative Methods Program of the Department of Psychology, University of Illinois at Urbana - Champaign. Parts were presented at the biennial meeting of the Society for Research and Action, New Haven, CT, 1999, and parts were written while the first author was at Wesleyan University. We gratefully acknowledge the contribution of the researchers and staff at Public/Private Ventures, particularly Nancy L. Resch, Jean Grossman, and Joseph P. Tierney, and the cooperation of Big Brothers/Big Sisters of America. We also appreciate the assistance of Karen Rudolph, David DuBois, and Lawrence Hubert.

\section{REFERENCES}

American Psychological Association (1992). Ethical principles of psychologists and code of conduct. Am. Psychol. 47: 1597-1611.
Arendell, T. (1997). A social constructionist approach to parenting. In Arendell, T. (ed.), Contemporary Parenting: Challenges and Issues. Sage, Thousand Oaks, CA.

Armsden, G. C., and Greenberg, M. T. (1987). The Inventory of Parent and Peer Attachment (IPPA): Relationship to well-being in adolescence. J. Youth Adolesc. 16: 427-454.

Aseltine, R. H., Dupre, M. and Lamlein, P. (2000). Mentoring as a drug prevention strategy: An evaluation of across ages. Adolesc. Fam. Health 1: 11-20.

Baumrind, D. (1968). Authoritarian vs. authoritative parental control. Adolescence 3: 255-272.

Baumrind, D. (1971). Current patterns of parental authority. Dev. Psychol. Monogr. 4: P. 2.

Ben-Zur, H. (2003). Happy adolescents: The link between subjective well-being, internal resources, and parental factors. J. Youth Adolesc. 32: 67-79.

Berndt, T., and Perry, B. (1986). Children's perceptions of friendships as supportive relationships. Dev. Psychol. 22: 640-648.

Berndt, T., and Miller, K. (1986). Expectancies, values, and achievement in junior high school. J. Educ. Psychol. 82: 319-326.

Davidson. W. S., II, Redner, R., Blakely, C. H., Mitchell, C. M., and Esmhoff, J. G. (1987). Diversion of juvenile offenders: An experimental comparison. J. Consult. Clin. Psychol. 55: 68-75.

Darling, N., Hamilton, S. F., and Niego, S. (1994). Adolescents' relations with adults outside the family. In Montemayor, R., and Adams, G. R. (eds.), Personal Relationships During Adolescence. Advances in Adolescent Development: An Annual Book Series, (Vol. 6). Sage, Thousand Oaks, CA, pp. 216-235.

DuBois, D. L., Holloway, B. E., Valentine, J. C., and Cooper, H. (2002). Effectiveness of mentoring programs for youth: A meta-analytic review. Am. J. Commun. Psychol. 30: 157-197.

DuBois, D. L., and Neville, H. A. (1997). Youth mentoring: Investigation of relationship characteristics and perceived benefits. J. Commun. Psychol. 25: 227-234.

Freedman, M. (1993). The Kindness of Strangers. Jossey-Bass, San Francisco.

Grossman, J. B., and Rhodes, J. (2002). The test of time: Predictors and effects of duration in youth mentoring relationships. Am.J. Commun. Psychol. 30: 199-219.

Grossman, J. B., and Tierney, J. P. (1998). Does mentoring work? An impact study of the Big Brothers Big Sisters Program. Eval. Rev. 22: 402-425.

Harter, S. (1986). Cognitive-developmental processes in the integration of concepts about emotions and the self. Special Issue: Developmental perspectives on social-cognitive theories. Soc. Cogn. 4: $119-151$.

Harter, S. (1985). Competence as a dimension of self-evaluation: Toward a comprehensive model of self-worth. In Leahy, R. L. (ed.), The Development of the Self. Academic Press, New York, pp. 55-121.

Helsen, M., Vollebergh, W., and Meeus, W. (2000). Social support from parents and friends and emotional problems in adolescence.J. Youth Adolesc. 29: 319-335.

Hoff-Ginsberg, E., and Tardiff, T. (1995). Socioeconomic status and parenting. In Bornstein, M. H. (ed.), Handbook of Parenting. Erlbaum, Mahwah, NJ, pp. 161-187.

Holmbeck, G. N., Paikoff, R. L., and Brooks-Gunn, J. (1995). Parenting adolescents. In Bornstein, M. H. (ed.), Handbook of Parenting. Erlbaum, Mahwah, NJ, pp. 91-118.

Howard, G. S., Nance, D. W., and Myers, P. (1986). Adaptive counseling and therapy: An integrative, eclectic model. Couns. Psychol. 14: 363-442.

Jarrett, R. L. (1995). Growing up poor: The family experiences of socially mobile youth in low-income African American neighborhoods. J. Adolesc. Res. 10: 111-135.

Jarrett, R. L. (1999). Successful parenting in high-risk neighborhoods. Future Chil. 9: 45-50.

Jordan, J. (1991). The meaning of mutuality. In Jordan, J. V., Kaplan, A. G., Miller, J. B., Stiver, I. P., and Surrey, J. L. (eds.), Women's Growth in Connection. Guilford Press, New York, pp. 81-96. 
Jöreskog, K. G., Sörbom, D., duToit, S., and du Toit, M. (2001). LISREL 8: New Statistical Features. Scientific Software International, Chicago.

Laible, D. J., Carol, G., and Raffaelli, M. (2000). The differential relations of parent and peer attachment to adolescent adjustment. $J$. Youth Adolesc. 29: 45-59.

Lamborn, S. D., Mounts, N. S., Steinberg, L., and Dornbusch, S. M. (1991). Patterns of competence and adjustment among adolescents from authoritative, authoritarian, indulgent, and neglectful families. Child Dev. 62: 1049-1065.

Linnehan, F. (2001). The relation of a work-based mentoring program to the academic performance and behavior of African American students. J. Vocat. Behav. 59: 310-325.

LoSciuto, L., Rajala, A. K., Townsend, T. N., and Taylor, A. S. (1996). An outcome evaluation across ages: An intergenerational mentoring approach to drug prevention. J. Adolesc. Res. 11: 116-129.

Luescher, K., and Pillemer, K. (1998). Intergenerational ambivalence: A new approach to the study of parent-child relations in later life. $J$. Marriage Fam. 60: 413-445.

Mason, C. A., Cauce, A. M., Gonzales, N., and Hiraga, Y. (1994). An ecological model of externalizing behaviors in African American adolescents: No family is an island. J. Res. Adolesc. 4: 639-655.

McKenna, T. (1998, June). Big Brothers/Big Sisters of America: A view from the national level. Paper presented at the Commonwealth Fund's Invited Conference on the State and Future of Mentoring Symposium, Washington, DC.

McPartland, J. M., and Nettles, S. M. (1991). Using community adults as advocates or mentors for at-risk middle school students: A twoyear evaluation of Project RAISE. Johns Hopkins Univ. Center Res. Eff. Sch. Disadvantaged Stud. 17: 1-12.
Mitchell, C. M., Kantrowitz, R. E., and Davidson, W. S., II (1980). Differential attitude change in nonprofessional experience: An experimental comparison. J. Counsel. Psychol. 27: 625-629.

Morrow, K. V., and Styles, M. B. (1995). Building Relationships With Youth in Program Settings: A Study of Big Brothers Big Sisters. Public/Private Ventures, Philadelphia.

Portes, P. R., Dunham, R. M., and Williams, S. (1986). Assessing childrearing style in ecological settings: Its relation to culture, social class, early age intervention and scholastic achievement. Adolescence 83: 723-731.

Rhodes, J. E. (2002). Stand By Me: The Risks and Rewards of Mentoring Today's Youth. Harvard University Press, Cambridge, MA.

Sipe, C. L. (1998). Mentoring adolescents: What have we learned? In Grossman, J. B. (ed.), Contemporary Issues in Mentoring. Public/Private Ventures, Philadelphia, pp. 24-47.

Steinberg, L., Darling, N., and Fletcher, A. (1995). Authoritative parenting and adolescent adjustment: An ecological journey. In Moen, P., Elder, G. H., Jr., and Luescher, K. (eds.), Examining Lives in Context: Perspectives on the Ecology of Human Development. American Psychological Association, Washington, DC, pp. $423-$ 466.

Styles, M. B., and Morrow, K. V. (1992). Understanding How Youth and Elders Form Relationships: A Study of Four Linking Lifetime Programs. Public/Private Ventures, Philadelphia.

van Wel, F., Linsen, H., and Abma, R. (2000). The perental bond and the well-being of adolescents and young adults. J. Youth Adolesc. 29: 307-318.

Wilkinson, L., Engelman, L., Corter, J., and Coward, M. (1996). Cluster analysis. In Wilkinson, L. (ed.), SYSTAT 6.0 for Windows. SPSS, Chicago, pp. 333-360. 